DOI: 10.20472/BMC.2019.010.008

\title{
DEDHY SULISTIAWAN
}

University of Surabaya, Indonesia

\section{FELIZIA ARNI RUDIAWARNI}

University of Surabaya, Indonesia

\section{IS PRICE TO EARNINGS RATIO (STILL) USEFUL FOR TRADING STRATEGY?}

\begin{abstract}
:
Overreaction phenomena stimulate assets mispricing and return reversals. Investors should build a trading strategy to receive benefits from the anomaly. Developing the classic idea of overreaction hypothesis from DeBondt and Thaler (1985 and 1990), we build stock portfolios based on sentiment and risk to produce higher future stock return. Using Indonesian data, we use financial information from public information to test weak-form efficiency. We believe that investors are not always rational and other groups of investors can use public information to generate excess return. This article finds that lower PER tend to produce higher future return, especially if lower PER accompanied by lower risk. Practically, our study contributes to the use of fundamental analysis in emerging markets. Theoretically, this study supports the idea of behavioral finance theory and reject weak-form efficient market hypothesis in Indonesia Stock Exchange.
\end{abstract}

\section{Keywords:}

Price Earnings Ratio (PER), Price to Book Value (PBV), stock risk, future return, trading strategy

JEL Classification: G11, G14 


\section{Introduction}

Overvaluation (undervaluation) leads to extreme future stock price changes. This phenomenon is well established in the literature. DeBondt and Thaler (1985) present the original idea of overreaction hypothesis, investors overreact to good (bad) information based on one of sentiment indicators, that is price earnings ratio (PER). We believe that it stimulates overvaluation (undervaluation). Campbell and Shiller $(1998,2001)$ and Weigand and Irons (2006) also give evidence about return reversal phenomenon. Analysts also contribute to overvaluation (undervaluation) (DeBondt and Thaler, 1990) that cause bigger gap of mispricing. Retail investors or noise traders who use analyst's information also suffer overreact bias. Higher (lower) PER tend to generate lower (higher) future stock return.

Developed markets produce more informative financial information. Then, PER should be used in investing decision. Previous studies (DeBondt and Thaler 1985 and 1990; Campbell and Shiller, 1998 and 2001; Weigand and Irons, 2006) use US data to present evidence about mispricing. This article adopts the topic by using Indonesian data, one of emerging stock markets. In Indonesia, the examination of the usefulness of PER in trading strategy is needed to generalize it. This stock markets produce lower market capitalization (Hartono and Sulistiawan, 2015), lower earnings informativeness (Landsman et al., 2012), and higher risk (Nwachukwu and Shitta, 2015). Those are different characteristics when comparing to US market. We expect to present the benefit of PER in generating return using developing market environment.

To develop research in this area, our study uses stock risk to enhance the effect of PER to future return. Indonesian market has higher standard deviation than many other countries in emerging markets (Nwachukwu and Shitta, 2015). That situation builds new chances to expand PER studies. We use risk to complement PER, because the usefulness of PER has been studied in developed countries that have a lower level of risk compared to developing countries. The use of risk as moderating variable is to create lower-risk portfolio in high-risk (emerging markets) environment.

Our results indicate that PER affects future return. After considering stock risk, we also find that low PER and low stock risk generates higher future return. It can be concluded that market is inefficient in the weak form. Current PER produce future return, especially firms with lower risk. 
Our study presents practical and theoretical benefits. The first, it contributes to the use of fundamental analysis, especially the use of PER, in emerging markets. The second, it supports the idea of behavioral finance that investors tend to overreact, and other investors can use it to get benefits from return reversal phenomenon.

This article is presented in several sections. The first section discusses the importance of this article. The second, we develop hypotheses. Data and methodology are discussed in the third section. The fourth section presents results and discussion, and the final section concludes.

\section{Hypothesis Development}

There are three form of efficient market hypothesis. Strong efficient market hypothesis believes that stock prices are reflected by all information, either published or inside information. Semistrong efficient market hypothesis states that public information will be absorbed by stock price when those are released in the market. The last form is weak-form efficient market. It discusses about how historical data is already reflected in stock price. This study focuses on the examination of weak-form efficiency.

The study of Fama and Blume (1966) that discuss weak-form of efficient market suggest that investors are not able to use historical data to generate extra return because stock price reflects historical data. In this case, theoretically, PER information as the representation of historical data has no prediction power to generate return because stock price is already adjusted after PER is released by a firm. When the markets are efficient, new information are used by market participants and it will be absorbed by stock price.

Our article uses behavioral finance theory to counter the idea of weak-form efficient market. The idea of producing return using PER is possible because human is not always rational. Higher (lower) PER leads to higher (lower) sentiment (Conrad et al., 2002). Overreaction to higher PER ultimately leads to overvaluation, and overvaluation will lead to the emergence of glamorous stock. Conversely, undervaluation will generate value stocks. So, informed investors can benefit by understanding other stock-trader behaviors. When most traders overreact to PER information, stock price is valued higher (lower) than it should be. After most of active traders realize that stock price is too high (low) they will reverse their position (DeBondt and Thaler, 1985). Reversal of position due to overvaluation will cause a decline in subsequent stock price and cause a negative return. The impact of this overvalued reversal is more severe than the price adjustment caused by undervaluation. This asymmetric response to good and bad news of published financial information is caused by investor psychology. This main idea is adopted by many popular investing books. For example, The Intelligent Investors and Security Analysis by Benjamin Graham. We expect that investors will receive benefits when building trading strategy based on PER.

Overvaluation (undervaluation) implicitly also represent lower earnings informativeness. When earnings is not informative, stock price movement is not based on earnings. Lower earnings that form positive stock return produce higher PER. Conversely, negative stock return of higher earnings firms generates lower PER. When firms in Indonesia presents lower earnings 
informativeness (Landsman et al., 2012 and Fan and Wong, 2002) there are many under (over) value stocks. Outside investors can use historical data to obtain extra return. Their action will present the anomaly of weak-form efficiency and support the idea of behavioral finance by selecting cheaper stocks. Based on those thoughts, we present our first hypothesis.

\section{H1: Lower (higher) PER produce higher (lower) future return.}

Indonesian market produces higher stock risk (Nwachukwu and Shitta, 2015). Using naïve model, we assume that current risk represents future expected return. Higher risk represents higher expected return that will decrease fundamental value. Selecting only lower risk in high risk environment should improve the power of PER strategy. The combination of PER and stock risk portfolio will produce different future return.

Based on investor perspective, most of investors prefer lower-risk stocks because in normal condition or positive domain, investors tend to become risk-adverse. Conversely, in negative domain or crisis condition, prospect theory suggests that investors become risk-taker and they will prefer higher-risk stocks. Market participants are the combination of both sides, risk-adverse and risk-takers investors. Hence, risk is an important factor to determine future return.

\section{H2: Stock risk affect the relation between PER and future return.}

\section{Data and methodology}

The object of this research is all firms listed in Indonesia Stock Exchange (IDX) in the period 2014 to 2017 and have complete data needed in the study. IDX is the representative of emerging stock markets. The overall data collected is 1,374 firm-years. We discard data with negative PER and negative PBV in order not to bias the results of the study, so that there are 1,056 firm years of research. We exclude the data with future return (proxied by Excess Return ${ }_{t+1}$ ) that is above and below the average \pm 3 standard deviation. Finally, we obtain 1,042 firm-years data as our object of study.

To test the hypothesis, we estimate the following regression:

$$
\text { ER }_{i, t}=\beta_{0}+\beta_{1} \text { PER }_{i, t-1}+\beta_{2} \text { Leverage }_{i, t-1}+\beta_{3} \text { Size }_{i, t-1}+\beta_{4} \text { EPS }_{i, t-1}+\beta_{5} \text { Risk }_{i, t-1}+\beta_{6} \text { PER }_{i, t-1} \text { XRisk }_{i, t-1}+\varepsilon_{i, t}
$$

\section{Where:}

$\begin{array}{ll}\text { ER } & =\text { Excess Return }\left(\mathrm{R}_{\digamma}-\mathrm{R}_{m}\right) \\ \text { PER } & =\text { Price to earnings ratio } \\ \text { Leverage } & =\text { Debt to total asset } \\ \text { Size } & =\text { Natural logarithm of total asset } \\ \text { EPS } & =\text { Earnings per share } \\ \text { Risk } & =\text { Standard deviation of weekly return } \\ \text { PERxRISK } & =\text { Interacting variable between PER and Risk. } \\ \varepsilon & =\text { PER (RISK) Low }=1 \text { and PER }(\mathrm{RISK}) \text { High }=0 \\ \mathrm{~T} & =\text { Curror } \\ \alpha, \beta & =\text { Coefficient of regression }\end{array}$


$H 1$ is supported when $\beta_{1<0 .} H 2$ is examined using $\beta_{6}$ coefficient. We expect that $\beta_{6}$ is different from zero.

\section{Result and Discussion}

Table 1 exhibits descriptive statistics of the variables in this study.

Table 1. Descriptive Statistics

\begin{tabular}{lcccc}
\hline Variable & Minimum & Maximum & Mean & Std. Deviation \\
\hline ER $_{i, t}$ & -1.1531 & 2.5589 & -0.0573 & 0.4986 \\
PER $_{i, t-1}$ & 0.5836 & 4222.1759 & 74.2611 & 318.8506 \\
Risk $_{i,-1}$ & 0.0000 & 1.4271 & 0.0607 & 0.0620 \\
Leverage $_{i, t-1}$ & 0.0003 & 0.9479 & 0.4924 & 0.2283 \\
Size $_{i,-1}$ & 24.5683 & 34.5768 & 28.8879 & 1.7627 \\
EPS $_{i, t-1}$ & 0.0435 & 17621.3787 & 205.4363 & 811.7418 \\
\hline
\end{tabular}

Table 1 shows that $\mathrm{ER}_{i, t}$ as the proxy of future returns has a negative means. This condition indicates that negative future returns dominate the data we use during the research period. There is a very large gap between the minimum and maximum value of $\mathrm{PER}_{i, t-1}$, indicating a very large gap between undervalued and overvalued stock. This very large gap is also depicted in EPS $S_{i, t-1}$. Hypothesis test results are shown in table 2.

Table 2. Regression analysis

\begin{tabular}{|l|c|c|c|c|}
\hline \multirow{2}{*}{$\begin{array}{l}\text { Independent } \\
\text { Variable }\end{array}$} & \multicolumn{2}{|c|}{ Model 1 } & \multicolumn{2}{c|}{ Model 2 } \\
\cline { 2 - 5 } Constant & Coeff. & t-value & Coeff. & t-value \\
\hline PER $_{i, t-1}$ & 0.279 & 1.048 & 0.266 & 1.000 \\
\hline Leverage $_{i, t-1}$ & $<0.001$ & $-2.296^{* *}$ & $<0.001$ & $-2.071^{* *}$ \\
\hline Size $_{i, t-1}$ & 0.214 & $2.943^{\star * *}$ & 0.209 & $2.882^{\star * *}$ \\
\hline EPS $_{i, t-1}$ & -0.014 & -1.521 & -0.015 & -1.558 \\
\hline Risk $_{i, t-1}$ & $<-0.001$ & $-1.711^{*}$ & $<-0.001$ & $-1.917^{*}$ \\
\hline PERXRISK & -0.137 & -0.510 & -0.005 & -0.017 \\
\hline F-test & \multicolumn{2}{|c|}{$3.9672^{\star * *}$} & 0.072 & $1.925^{*}$ \\
\hline Adj $R^{2}$ & \multicolumn{2}{|c|}{0.014} & \multicolumn{2}{c|}{$3.9324^{\star * *}$} \\
\hline
\end{tabular}

Dependent variable: $\mathrm{ER}_{i, t}$ (excess return firm $\mathrm{i}$ in period $\mathrm{t}$ )

PERxRISK is an interacting variable between PER and Risk. (PER (RISK) Low =1 PER (RISK) High $=0$ )

Low PER $($ RISK) $=$ PER (RISK) lower than and equal to median. High PER (RISK) $=$ PER (RISK) higher than Median

${ }^{*},{ }^{* *},{ }^{* * *}$ significant at $10 \%, 5 \%$ and $1 \%$ respectively (two-tailed test)

Table 2 shows that PER has a significant negative effect on future returns. This finding shows that undervalued stocks (low PER) have a higher return in the future. This result is applies for both Model (Model 1 and Model 2). So, $\mathrm{H}_{1}$ is supported. 
Based on the result in Table 2, we see that risk cannot explain future return. However, if PER and Risk are interacted, it can be seen that risk affect the relation between PER and future return. This finding supports for $\mathrm{H}_{2}$.

In both model, we see that Leverage has positive impact to future return. This result is in accordance with the risk premium hypothesis, that higher leverage is associated with higher rates of return (Hurdle, 1974). Current EPS has a negative effect on future returns. This may occur due to the future return of the object of this research, many of which are negative.

To improve the discussion, we also conduct an independent sample t-test of future return for stocks based on low PER (group A) and high PER (group B). The result is shown in Table 3. The difference in future returns from the two groups is significant with higher future return for groups of low PER stocks (Group A).

Table 3. Test of differences: Future return based on Low PER and High PER Group

\begin{tabular}{cccc}
\hline Group & Mean ER $_{i, t}$ & $\mathrm{~T}$ & Sig (2-tailed) \\
\hline Group A (Low PER) & -0.02508 & \multirow{2}{*}{2.091} & $0.037^{\star *}$ \\
Group B (High PER) & -0.08956 & & \\
\hline
\end{tabular}

$\mathrm{ER}_{i, t}=$ excess return firm $\mathrm{i}$ in period $\mathrm{t}$

${ }^{*},{ }^{* *},{ }^{* * *}$ significant at $10 \%, 5 \%$ and $1 \%$ respectively

\section{Additional Analysis}

Return is inseparable from the accompanying risk. Extending the analysis, in this study we also add risk as one of the important factors in explaining future returns. In this additional analysis, we divide the stock group based on risk (high $=0$ and low $=1$ ) and PER (high $=0$ and low $=1$ ). Table 4 shows the independent t-test among those groups.

Table 4. Test of differences in future return for Low PER and High PER Group

\begin{tabular}{|c|c|c|c|}
\hline Group & Mean $\mathrm{ER}_{i, t}$ & $\mathrm{~T}$ & Sig (2-tailed) \\
\hline Group 1 & -0.087463 & \multirow{2}{*}{0.090} & \multirow{2}{*}{0.9276} \\
\hline Group 2 & -0.091335 & & \\
\hline Group 1 & -0.087463 & \multirow{2}{*}{-0.7752} & \multirow{2}{*}{0.4386} \\
\hline Group 3 & -0.050686 & & \\
\hline Group 1 & -0.087463 & \multirow{2}{*}{-1.9898} & \multirow{2}{*}{$0.0472^{* *}$} \\
\hline Group 4 & 0.003759 & & \\
\hline Group 2 & -0.091335 & \multirow{2}{*}{-0.9718} & \multirow{2}{*}{0.3316} \\
\hline Group 3 & -0.050686 & & \\
\hline Group 2 & -0.091335 & \multirow{2}{*}{-2.3771} & \multirow{2}{*}{$0.0178^{* *}$} \\
\hline Group 4 & 0.003759 & & \\
\hline Group 3 & -0.050686 & \multirow{2}{*}{1.2057} & \multirow{2}{*}{0.2285} \\
\hline Group 4 & 0.003759 & & \\
\hline
\end{tabular}

$\mathrm{ER}_{i, t}=$ excess return firm $\mathrm{i}$ in period $\mathrm{t}$

${ }^{*},{ }^{* *},{ }^{* *}$ significant at $10 \%, 5 \%$ and $1 \%$ respectively 
Group 1 refers to stocks with High PER and High Risk. Group 2 refers to stocks with High PER and Low Risk. Group 3 refers to stocks with Low PER and High Risk. Group 4 refers to stocks with Low PER and Low Risk.

Low PER $(\mathrm{RISK})=$ stock with PER (RISK) below the median

High PER $($ RISK $)=$ stock with PER (RISK) above the median

Table 4 shows that future return $\left(E R_{i, t}\right)$ of Group 4 is positive. It is superior to other groups although, statistically, there is no difference between Group 3 and 4. Independent sample t-test shows that Group 4's ER $\mathrm{E}_{i, t}$ is significantly different from Group 1 and Group 2. This result supports the previous test which shows that comparing to stocks with high PER, stock with low PER can produce higher future returns.

Our findings provide evidence that PER is still useful implemented in Indonesia Stock Exchange. Investors still receive benefits from historical data. These results reject weak-form efficient market hypothesis and support behavioral finance theory. Investors are not fully rational, and they can use public information to produce excess return. Overreaction (underreaction) produce glamour (value) stocks that generate better investing performance. At present there is still mispricing caused by sentiment. We believe that the understanding of behavioral finance is important for investors.

\section{Conclusion}

Researches on stock valuation is mostly done to build successful trading strategies. PER is one of popular tools for valuing stocks and predicting future returns. This study developes the idea of DeBondt and Thaler (1985) regarding the overreaction hypothesis. The market experiences overreaction, so certain stocks become more overvalued (undervalued). But the market participants slowly realize the overreaction phenomenon and bring prices back to their underlying value. Therefore, stocks that are currently overvalued (high PER), in the future, the market believe reverses so that the price for this kind of stocks will decrease, and therefore will produce a lower future return. On the contrary, stocks that are currently undervalued (low PER), investors adjust the mispricing so that in the future undervalued stocks tend to produce higher future return.

Risk is inseparable from return. In this study we also examine risk as one of the explanatory factors for future returns. Low PER (value) stocks generate a higher future return compared to a high PER (glamour) stocks, especially if the low PER stocks also have a low risk.

This study provides a theoretical contribution to the development of behavioral finance by realizing that market participants are not fully rational. They experience overreaction as stated in DeBondt and Thaler (1985 and 1990). Practically, investors can exploit this overreaction to obtain a higher future return by conducting a fundamental analysis through PER and risk.

\section{References}

BHARGAVA, V. and MALHOTRA, D. K. (2006). Do Price-Earnings Ratios Drive Stock Values?. The Journal of Portfolio Management. 2006, Vol. 33, No. 1, s. 86-92. 
CAMPBELL, J. Y. and SHILLER, R. J. (1998). Valuation Ratios and the Long-Run Stock Market Outlook. The Journal of Portfolio Management. 1998, Vol. 24, s. 11-26. (2001). Valuation Ratios and the Long-Run Stock Market Outlook: An Update. Cowles Foundation Discussion Paper No. 1295, Yale University, March 2001.

CONRAD, J., CORNELL, B. and LANDSMAN, W. R. (2002). When Is Bad News Really Bad News?. The Journal of Finance. 2002, Vol. 57, No. 6, s. 2507-2532.

DE BONDT, W. F. and THALER, R. (1985). Does the Stock Market Overreact?. The Journal of Finance. 1985, Vol. 40, No. 3, s. 793-805.

DE BONDT, W. F. and THALER, R. H. (1990). Do security analysts overreact?.

FAMA, E. F. and BLUME, M. E. (1966). Filter Rules And Stock-Market Trading. The Journal of Business. 1966, Vol. 39, No. 1, s. 226-241.

FAN, J. P. and WONG, T. J. (2002). Corporate Ownership Structure and the Informativeness of Accounting Earnings in East Asia. Journal of Accounting and Economics. 2002, Vol. 33, No 3, s. 401-425.

HARTONO, J. and SULISTIAWAN, D. (2015). Performance of Technical Analysis in Declining Global Markets. Global Journal of Business Research. 2015, Vol. 9, No. 2, s. 41-52.

HURDLE, G. J. (1974). Leverage, Risk, Market Structure and Profitability. The Review of Economics and Statistics.1974, Vol. 56, No. 4 (Nov. 1974), s. 478-485.

LANDSMAN, W. R., MAYDEW, E. L. and THORNOCK, J. R. (2012). The Information Content of Annual Earnings Announcements and Mandatory Adoption of IFRS. Journal of Accounting and Economics. 2012, Vol. 53, No. 1-2, s. 34-54.

NWACHUKWU, J. C. and SHITTA, O. (2015). Testing the Weak-Form Efficiency of Stock Markets: A Comparative Study of Emerging and Industrialised Economies. International Journal of Emerging Markets. 2015, Vol. 10, No. 3, s. 409-426.

WEIGAND, R. A. and IRONS, R. (2007). The Market P/E Ratio, Earnings Trends, and Stock Return Forecasts. Journal of Portfolio Management. 2007, Vol. 33, No. 4, s. 87-101. 